\title{
Disinfectant use as a risk factor for atopic sensitization and symptoms consistent with asthma: an epidemiological study
}

\author{
L. Preller*+†, G. Doekes*, D. Heederik*, R. Vermeulen*, \\ P.F.J. Vogelzang**, J.S.M. Boleij*++
}

Disinfectant use as a risk factor for atopic sensitization and symptoms consistent with asthma: an epidemiological study. L. Preller, G. Doekes, D. Heederik, R. Vermeulen, P.F.J. Vogelzang, J.S.M. Boleij. C CERS Journals Ltd 1996.

ABSTRACT: Exposure to some nonallergenic compounds has been shown to increase the risk of atopic sensitization and asthmatic symptoms. In order to gain more insight into the largely unknown aetiology of respiratory symptoms in pig farmers, we studied the role of nonallergic exposure.

We evaluated associations between chronic respiratory symptoms, specific and total serum immunoglobulin E (IgE) levels, use of disinfectants, and endotoxin exposure levels in a population of 194 Dutch pig farmers.

Atopic sensitization (defined as increased production of IgE to common allergens) was found to occur more frequently in farmers who used disinfectants containing quaternary ammonium compounds (QACs) (odds ratio (OR) 7.4; 95\% confidence interval (95\% CI) 1.3-43.1). ORs for other disinfectants ranged 2.3-4.1 (NS). Atopic sensitization was not found to occur more frequently in farmers with a high endotoxin exposure. The use of disinfectants was only related to respiratory symptoms consistent with asthma in atopics. This is illustrated by the significantly elevated ORs for farmers with IgE to common allergens (house dust mite, grass pollen, birch pollen), and who used disinfectants containing QACs, in the total population and in a subgroup of the total population restricted according to bronchial hyperresponsiveness to histamine (symptomatics with a provocation dose of histamine producing a $\geq 10 \%$ decrease in forced expiratory volume in one second (PC10) $\leq 16$ $\mathrm{mg} \cdot \mathrm{mL}^{-1}$, compared with asymptomatics with a PC10 $\left.>16 \mathrm{mg} \cdot \mathrm{mL}^{-1}\right)(\mathrm{OR} 4.4,95 \%$ CI 1.3-14.6; and OR 8.2, 95\% CI 1.6-42.6, respectively). Atopy and use of QACs and endotoxin exposure level taken individually were not associated with respiratory symptoms. A combination of atopic sensitization and high endotoxin exposure $\left(>101 \mathrm{ng}^{-3} \mathrm{~m}^{-3}\right)$ was strongly associated with respiratory symptoms in the restricted population (OR 6.1; 95\% CI 1.0-36.2).

Our results suggest that occupational exposure to nonallergenic agents (disinfectants) may induce immunoglobulin $E$ sensitization to common aeroallergens, and that the combination of atopy and exposure to nonallergenic agents (disinfectants and endotoxin) is an important risk factor for development of symptoms consistent with asthma.

Eur Respir J., 1996, 9, 1407-1413.
*Dept of Epidemiology and Public Health, Wageningen Agricultural University, The Netherlands. +Dept of Air Quality, Wageningen Agricultural University, The Netherlands. ${ }^{\dagger}$ Animal Health Service in The Southern Netherlands, Boxtel, The Netherlands. **Dept of Occupational Medicine, University of Nijmegen, The Netherlands. ${ }^{++}$Board for the Authorization of Pesticides, Wageningen, The Netherlands.

Correspondence: D.J.J. Heederik Wageningen Agricultural University Dept of Epidemiology and Public Health PO Box 238

$6700 \mathrm{AE}$ Wageningen

The Netherlands

Keywords: Adjuvant disinfectants

endotoxin

occupational exposure

quaternary ammonium compounds

Received: August 141995

Accepted after revision January 301996

This study was part of the European Union concerted action "Epidemiology of occupational allergic asthma and exposure to bioaerosols", contract No. BMH1-CT941446.
Allergic respiratory disorders, including asthma, are characterized by an increased production of allergen specific immunoglobulin E (IgE) antibodies. Sensitization, and subsequent development of allergic respiratory symptoms, depend on intrinsic and extrinsic factors. The inherited propensity to produce specific $\operatorname{IgE}$ antibodies in response to environmental allergens is of primary importance, and allergen exposure has been shown to be a relevant risk factor both for atopic sensitization and for the induction of respiratory symptoms in sensitized individuals $[1,2]$. However, not all genetically predisposed and allergen-exposed subjects become sensitized, and not all sensitized and exposed individuals develop allergic asthma. Thus, other co-factors determine the risk of atopic sensitization and development of asthma [2, 3].

Results of human experimental and epidemiological studies indicate that exposure to nonallergenic air pollutants might be a co-factor in the onset of allergic disease or in exacerbation of symptoms [4-6]. These air pollutants may also act as co-factors in atopic sensitization. This suggestion is based mainly on results of experimental animal studies, in which exposure to ozone, diesel exhaust particles, and $\mathrm{SO}_{2}$, combined with exposure to airborne allergens, resulted in increased risk of atopic sensitization [7-9]. Combined exposures to allergens and nonallergenic air pollutants are very common in indoor, outdoor and occupational environments. However, despite increased interest in the role of air pollutants as cofactors that modify the response to allergens, no studies have so far reported that exposure to such pollutants in these environments was associated with an increase in atopic sensitization. 
In this report, we describe epidemiological findings in a group of pig farmers. This occupational group is exposed to a variety of airway irritants: manure gases; chemicals used for disinfection; and bacterial endotoxins from manure and animal feed. Pig farmers are also exposed to potential allergens originating from storage mites, animals and feed. The prevalence of work-related respiratory symptoms is known to be high among pig farmers, but the aetiology requires further clarification [10]. Some chemical components used in disinfectants are suspected adjuvants [11]. Endotoxin has also been suggested as a potential adjuvant in experimental animal studies, and its most active component, lipopolysaccharide (LPS), is widely-used in in vitro studies as a potent B-cell mitogen and co-factor for immunoglobulin production [12]. There have been indications that nonallergenic exposures of pig farmers could potentially act as adjuvants. We therefore studied the associations between these exposures and atopic sensitization, and to what extent atopic sensitization and nonallergenic exposures may be risk factors for chronic respiratory and asthma-like symptoms.

\section{Methods}

\section{Population and health data}

The population consisted of 194 pig farmers, living in the two south-eastern provinces of The Netherlands. The population was recruited from a group of 1,133 male owners of pig farms, who worked for at least $5 \mathrm{~h} \cdot \mathrm{day}^{-1}$ in pig farming. Selection was based on chronic respiratory symptoms reported in the Dutch version of a self-administered shortened questionnaire on respiratory symptoms of the British Medical Research Council [13]. All farmers $(n=94)$ with more than one symptom of chronic cough, chronic phlegm, ever wheezing, frequent wheezing, shortness of breath, and chest-tightness (asthma) were selected for further analysis. A group of 100 asymptomatic farmers was selected at random from 757 symptom free farmers.

In a subsequent medical survey held in winter 1990/ 1991, venous blood samples were taken for analysis of IgE antibodies. Bronchial responsiveness was tested in the farmers by histamine provocation according to a modified procedure of the method described by COCKCROFT et al. [14]. The histamine concentration ranged 0.03-16 $\mathrm{mg} \cdot \mathrm{mL}^{-1}$. Lung function measurements were performed using a Vicatest-V dry "rolling seal" spirometer (Mijnhardt, Bunnik, The Netherlands). Measurements and procedures including correction for body temperature, atmospheric pressure and water saturation (BTPS) and procedures of data selection were in accordance with the recommendations of the European Coal and Steel Community (ECSC) [15]. Baseline lung function level was compared to age and standing height specific reference values as proposed by the ECSC [15].

\section{IgE measurements}

Sera were stored at $-20^{\circ} \mathrm{C}$ until $\mathrm{IgE}$ analysis. Total serum $\operatorname{IgE}$ was determined with a sandwich enzyme immunoassay (EIA), in which diluted serum samples (routinely $1 / 10,1 / 20$ and $1 / 40$ ) were incubated in microwells coated with monoclonal mouse anti-human IgE (Central Laboratory of The Netherlands Red Cross Blood Transfusion Service (CLB), Amsterdam), and bound IgE was quantified with a peroxidase conjugate prepared from the same monoclonal anti-IgE (CLB), and ortho-phenylenediamine (OPD) as the peroxidase substrate. The assay was calibrated by including in each assay serial dilutions of IgE reference preparations containing 1,000 immunizing units (IU) $\cdot \mathrm{mL}^{-1}$ (Kabi Pharmacia). The assay has a sensitivity of approximately $1 \mathrm{IU} \cdot \mathrm{mL}^{-1}$, and intra- and interassay coefficient of variation $(\mathrm{CV})$ values of less than $15 \%$ [16].

Specific IgE to house dust mite (Dermatophagoides pteronyssinus), grass pollen (1:1 mixture of Lolium perenne and Phleum pratense), birch pollen (Betula verrucosa) and cat allergen was assessed with a modification of an EIA described previously [17]. Microwells were coated at $0.025 \mathrm{mg} \cdot \mathrm{mL}^{-1}$ with commercially available lyophilized extracts (ALK Benelux, Houten, The Netherlands) of the allergens. Sera were incubated at a 1/10 dilution, and bound $\operatorname{IgE}$ was measured by subsequent incubations with monoclonal mouse anti-human IgE (1/16,000; CLB), biotinylated rabbit anti-mouse immunoglobulin $\mathrm{G}(\mathrm{IgE})$ (1/5000; Dakopatts, Copenhagen, Denmark), avidin-peroxidase (1/2000; Dako) and OPD. This assay correlates well with commercially available test kits for specific serum IgE, and has a similar sensitivity and specificity with regard to skin-prick tests [16]. In each plate, sera containing $\operatorname{IgE}$ to the tested allergens were included as positive controls.

All serum-allergen combinations giving an optical density (OD) value exceeding the OD+3 SD of the reagent blank (no serum control) were retested, all on the same day, together with an equal number of randomly selected negative sera. In the second assay, the OD+3 SD was also used as the cut-off value. In this way, a small number of sera with a weakly positive reaction in the first test were eventually classified as negative, whilst all of the retested negative serum-allergen combinations remained negative in the second test.

$\mathrm{IgE}$ reacting with chloramine- $\mathrm{T}$ was assessed in microwells coated with human serum albumin and treated with chloramine- $\mathrm{T}$ and $\mathrm{Na}_{2} \mathrm{~S}_{2} \mathrm{O}_{3}$ [18]. The binding of specific $\operatorname{IgE}$ was quantified as described above. IgE with a specificity for quaternary ammonium compounds (QACs) was assessed using the Phadezym radioallergosorbent tests (RAST) method (Kabi Pharmacia, Uppsala, Sweden), with discs containing suxamethonium. The test was carried out in a selected group of 40 pig farmers, including all 19 using disinfectants containing QACs only, and 21 using QAC in combination with other active compounds.

\section{Exposure data}

Most farmers use disinfectants when cleaning animal housing, and generally use the disinfectants about once a week for less than $15 \mathrm{~min}$. Information on use and type of disinfectant was obtained by a visit to the farm. All visits were made by the same trained interviewer. Disinfectants were categorized according to active ingredients. Most commonly used disinfectants contain QACs, with 
or without aldehydes (glutaraldehyde, glyoxal, formaldehyde), or chloramine-T.

Personal dust samples were taken twice and analysed for endotoxin, according to procedures described by Hollander et al. [19]. A mathematical modelling technique, using data on farm characteristics and time spent on activities in pig farming during two full weeks, was used to estimate long-term average exposure to endotoxins [20]. In this way, data on endotoxin exposure were available for 164 farmers.

\section{Data analysis}

Differences between symptomatic and asymptomatic farmers were first tested using Chi-squared tests and ttests. Associations between chronic respiratory symptoms and $\operatorname{IgE}$ sensitization to common allergens as outcome variables and risk factors were further evaluated by means of a multiple logistic regression analysis (Statistical Analysis System guide for personal computers (SAS/PC) version 6.04 [21] PROC Logistic). Associations between respiratory symptoms and risk factors were studied in the entire population and in a population restricted according to bronchial hyperresponsiveness to histamine. Bronchial hyperresponsiveness was defined as a decrease in forced expiratory volume in one second $(\mathrm{FEV} 1)$ of at least $10 \%$ at a histamine concentration $\leq 16 \mathrm{mg} \cdot \mathrm{mL}$ (provocation concentration of histamine causing a $\geq 10 \%$ decrease in FEV1 $\left.(\mathrm{PC} 10) \leq 16 \mathrm{mg} \cdot \mathrm{mL}^{-1}\right)$ [22]. This selection procedure was applied to increase the contrast between cases and referents. Asymptomatic farmers with bronchial hyperresponsiveness $(n=17)$ were excluded from the referent group, and symptomatic farmers without bronchial hyperresponsiveness $(n=53)$ were excluded from the case group.

IgE sensitization to common allergens was defined as a positive reaction to one or more common allergens. Total IgE levels were dichotomized, with $100 \mathrm{IU} \cdot \mathrm{mL}^{-1}$ taken as cut-off level. Exposure to endotoxins was dichotomized by taking the median exposure level of $101 \mathrm{ng} \cdot \mathrm{m}^{-3}$ observed in this population as cut-off point.

\section{Results}

\section{Population}

Table 1 presents an overview of the study population, for the entire population of 194 farmers and the restricted population of 124 , farmers consisting of the 41 with chronic respiratory symptoms and a positive histamine threshold test $\left(\mathrm{PC}_{10} \leq 16 \mathrm{mg} \cdot \mathrm{mL}^{-1}\right)$, and the 83 farmers

Table 1. - Characteristics of the population of 194 Dutch pig farmers and the population restricted according to bronchial hyperresponsiveness to histamine

\begin{tabular}{|c|c|c|c|c|c|c|c|c|}
\hline \multirow[b]{4}{*}{ Age yrs $^{\#}$} & \multirow{2}{*}{\multicolumn{4}{|c|}{$\begin{array}{c}\text { Entire population } \\
\text { Symptoms }\end{array}$}} & \multirow{2}{*}{\multicolumn{4}{|c|}{$\begin{array}{c}\text { Restricted population } \\
\text { Symptoms } \$ \text { BHR }\end{array}$}} \\
\hline & & & & & & & & \\
\hline & \multicolumn{2}{|c|}{$\begin{array}{c}\text { No } \\
(n=100)\end{array}$} & \multicolumn{2}{|c|}{$\begin{array}{c}\text { Yes } \\
(\mathrm{n}=94)\end{array}$} & \multicolumn{2}{|c|}{$\begin{array}{l}\text { No/No } \\
(n=83)\end{array}$} & \multicolumn{2}{|c|}{$\begin{array}{c}\text { Yes/Yes } \\
(\mathrm{n}=41)\end{array}$} \\
\hline & 36 & (9) & 40 & $(10)$ & 35 & (8) & 43 & $(10)$ \\
\hline \multicolumn{9}{|l|}{ Smoking habits $\mathrm{n} \# \#$} \\
\hline Current & 18 & (18) & 42 & $(45)^{*}$ & 14 & (17) & 21 & $(51)^{*}$ \\
\hline Ex-smoker & 32 & (32) & 30 & (32) & 27 & (33) & 11 & (27) \\
\hline Lifelong nonsmoker & 50 & $(50)$ & 22 & $(23) *$ & 42 & $(51)$ & 9 & $(22) *$ \\
\hline $\mathrm{PC} 10 \leq 16 \mathrm{mg}$ histamine $\cdot \mathrm{mL}^{-1} \mathrm{n}^{\# \#}$ & 17 & (17) & $41 / 91$ & $(45) *$ & 0 & (0) & 41 & $(100) *$ \\
\hline FVC $\%$ pred ${ }^{\#}$ & 111 & (13) & 105 & $(13) *$ & 112 & (13) & 103 & $(13)^{*}$ \\
\hline $\mathrm{FEV}_{1} \%$ pred $^{\#}$ & 106 & (15) & 95 & $(17)^{*}$ & 109 & (13) & 87 & $(18)^{*}$ \\
\hline \multicolumn{9}{|l|}{ IgE to common allergens $n^{\# \#}$} \\
\hline 1 or more & 13 & (13) & 19 & (20) & 12 & $(15)$ & 7 & $(17)$ \\
\hline House dust mite & 7 & (7) & 14 & $(15)^{* *}$ & 6 & (7) & 7 & $(17) * *$ \\
\hline Grass pollen & 6 & (6) & 5 & (5) & 5 & (6) & 1 & (2) \\
\hline Birch pollen & 3 & (3) & 2 & (2) & 3 & (4) & 0 & $(0)$ \\
\hline Cat allergens & 0 & (0) & 0 & $(0)$ & 0 & (0) & 0 & $(0)$ \\
\hline Total IgE $>100 \mathrm{IU} \cdot \mathrm{mL}^{-1} \mathrm{n}^{\# \#}$ & 22 & (22) & 30 & (32) & 19 & (23) & 16 & $(39)^{* *}$ \\
\hline Total IgE IU $\cdot \mathrm{mL}^{-1+}$ & 28 & & 46 & & 28 & & 61 & \\
\hline \multicolumn{9}{|l|}{ Disinfectant $\mathrm{n}^{\# \#}$} \\
\hline None & 19 & (19) & 11 & (12) & 19 & (23) & 5 & (12) \\
\hline Chloramine- $\mathrm{T}$ & 25 & (25) & 28 & (30) & 21 & (25) & 13 & (32) \\
\hline QAC & 11 & (11) & 8 & (9) & 8 & $(10)$ & 6 & (15) \\
\hline QAC + aldehydes & 25 & (25) & 24 & (26) & 19 & (23) & 8 & (20) \\
\hline $\mathrm{QAC}+$ aldehydes + chloramine- $\mathrm{T}$ & 7 & (7) & 10 & (11) & 6 & (7) & 5 & (12) \\
\hline Other & 13 & (13) & 13 & (14) & 10 & (12) & 4 & (10) \\
\hline Endotoxin $\mathrm{ng} \cdot \mathrm{m}^{-3+}$ & 102 & & 104 & & 100 & & 111 & \\
\hline
\end{tabular}

\#: mean, and SD in parenthesis; \#\#: absolute number, and percentage in parenthesis; +: median value. $\$$ : chronic cough, chronic phlegm, ever wheezing, frequent wheezing, shortness of breath, and/or chest-tightness (asthma); BHR: bronchial hyperresponsiveness ( $\mathrm{PC} 10$ histamine $>16 \mathrm{mg} \cdot \mathrm{ml}^{-1}$ vs $\mathrm{PC} 10 \leq 16 \mathrm{mg} \cdot \mathrm{mL}^{-1}$ ); $\mathrm{PC} 10$ : provocative dose of histamine causing a $\geq 10 \%$ decrease in FEV1: FVC: forced vital capacity; FEV1: forced expiratory volume in one second; \% pred: percentage of predicted value; IgE: immunoglobulin E; QACs: quarternary ammonium compounds. *: $\mathrm{p}<0.05$; **: $\mathrm{p}<0.01$. 
without chronic respiratory symptoms and a negative histamine threshold test. The cases in the restricted population had predominantly reported symptoms indicative of variable airflow obstruction (ever wheezing, frequent wheezing, shortness of breath, and/or chest-tightness (asthma)). Relatively few farmers in the restricted case group reported only bronchitis-like symptoms (chronic cough and/or chronic phlegm). In the entire population, 32 farmers had detectable IgE levels to one or more of the common allergens, but none to cat allergens. Fifty three farmers had a total IgE level exceeding $100 \mathrm{IU} \cdot \mathrm{mL}^{-1}$. None of the 194 farmers had detectable specific IgE to chloramine-T, and two out of 40 farmers using QAC reacted positively to QACs, (RAST class 1 and 2, respectively (not shown in table)).

The crude data in table 1 show that cases and controls differed with respect to age, smoking habits, baseline lung function, and $\operatorname{IgE}$ sensitization to house dust mite $(\mathrm{p}<0.1)$. Total IgE levels were higher among symptomatic than asymptomatic farmers only in the restricted population. Although the use of disinfectants seemed to be more common among symptomatic than asymptomatic farmers, differences were not statistically significant.

To study risk factors of IgE sensitization, associations between sensitization, exposure and potential confounding factors were first tested in the entire population in univariate models. Age was strongly and inversely related to sensitization to common allergens (table 2), whereas smoking was only weakly related to sensitization. In the model testing the association with type of disinfectant, using dummy variables for five categories of disinfectants, the use of QACs was strongly and positively associated with sensitization to common allergens. Associations for other disinfectants were positive but not statistically significant. Exposure to high concentrations of endotoxins $\left(>101 \mathrm{ng} \cdot \mathrm{m}^{-3}\right)$ was not associated with specific sensitization to common allergens. In subsequent multiple logistic regression analyses, associations were adjusted for smoking habits and age. Associations between specific sensitization to common allergens and use of disinfectants were stronger than found in univariate analyses (table 3). The odds ratio (OR) for the use of unmixed QACs was 7.4 (95\% confidence interval (95\% CI) 1.3-43.1). The association with QACs mixed with aldehydes was borderline statistically significant (OR 4.1;

Table 2. - Odds ratio (OR) and 95\% confidence interval $(95 \% \mathrm{Cl})$ for the associations between atopy§, personal characteristics and use of disinfectants $(n=194)$ and endotoxin exposure $(n=164)$, calculated in univariate logistic regression analysis

\begin{tabular}{lll}
\hline & OR & $(95 \% \mathrm{CI})$ \\
\hline Current smoking (yes/no) & 0.9 & $0.37-2.0$ \\
Age (per 10 yrs) & 0.6 & $0.4-0.9$ \\
Chloramine-T & 2.5 & $0.5-12.6$ \\
QAC & 6.5 & $1.2-36.5$ \\
QAC + aldehydes & 3.6 & $0.7-17.7$ \\
QAC + aldehydes + chloramine-T & 1.9 & $0.2-14.6$ \\
Other & 2.6 & $0.4-15.2$ \\
Endotoxin exposure & 0.9 & $0.4-2.0$ \\
$\left(>101 \mathrm{vs} \leq 101 \mathrm{ng} \cdot \mathrm{m}^{-3}\right)$ & & \\
\hline
\end{tabular}

§: immunoglobulin $\mathrm{E}(\mathrm{IgE})$ to $\geq 1$ common allergen. QAC: quarternary ammonium compounds.
Table 3. - Odds ratio (OR) and 95\% confidence interval for the associations between atopy§ and use of disinfectants $(n=194)$ and endotoxin exposure $(n=164)$ calculated in a multiple logistic regression analysis, corrected for age and smoking

\begin{tabular}{lccc}
\hline & $\mathrm{n}$ & $\mathrm{OR}$ & $95 \% \mathrm{CI}$ \\
\hline Model 1: disinfectants & & & \\
No disinfectants & 30 & 1.0 & \\
Chloramine-T & 53 & 2.9 & $0.6-15.0$ \\
QAC & 19 & 7.4 & $1.3-43.1$ \\
QAC + aldehydes & 49 & 4.1 & $0.8-20.5$ \\
QAC + aldehydes + chloramine-T & 17 & 2.3 & $0.3-18.7$ \\
Other & 26 & 2.6 & $0.4-16.0$ \\
& & & \\
Model 2: endotoxin exposure & & 1.0 & $0.4-2.3$ \\
$>101$ vs $\leq 101$ ng.mg &
\end{tabular}

$\S$ : immunoglobulin $\mathrm{E}(\mathrm{IgE})$ to $\geq 1$ common allergen. QACs: quarternary ammonium compounds.

95\% CI 0.8-20.5). The association with endotoxin exposure remained statistically insignificant. There were no indications that total $\operatorname{IgE}$ level was associated with either use of disinfectants or level of endotoxin exposure (data not shown).

\section{Respiratory symptoms and risk factors}

In multiple logistic regression analyses, associations between respiratory symptoms, IgE sensitization to common allergens and exposure were studied, adjusted for smoking habits (current smoking yes/no) and age. Exposure to nonallergenic agents and IgE sensitization to common allergens were considered as potentially independent as well as interacting risk factors of chronic respiratory symptoms. The results of this analysis showed that farmers who used disinfectants containing QACs and had specific IgE to common allergens had significantly more symptoms than farmers who only used disinfectants (and were not sensitized to common allergens) (table 4, model 1). Atopic sensitization to common allergens or use of QACs were separately only weakly or were not associated with respiratory symptoms, with ORs close to 1. The association between symptoms and the combination of QACs and atopic sensitization to common allergens was strongest within the population restricted according to bronchial hyperresponsiveness, the OR being $8.2(95 \%$ CI 1.6-42.6). The interaction term in the model made a contribution of borderline statistical significance to improvement of the fit of the model $(\mathrm{p}<0.1)$.

The associations with the level of endotoxin exposure were tested in a similar way. In the restricted population, a high exposure level $\left(>101 \mathrm{ng} \cdot \mathrm{m}^{-3}\right)$ and specific IgE sensitization to common allergens were independently only moderately associated with respiratory symptoms, but the combination of both risk factors was strongly associated with respiratory symptoms, with an estimated OR of 6.1 (95\% CI 1.0-36.2), (table 4, model 2). The fit of the model with interaction term remained similar to that of the model without interaction term. The combination of risk factors was not significantly associated with respiratory symptoms in the entire population. 
Table 4. - Odds ratio (OR) and 95\% confidence intervals $(95 \% \mathrm{Cl})$ for the associations between respiratory symptoms, atopy§ and exposure to QACs or endotoxins calculated in a multiple logistic regression analysis, corrected for age and smoking habits

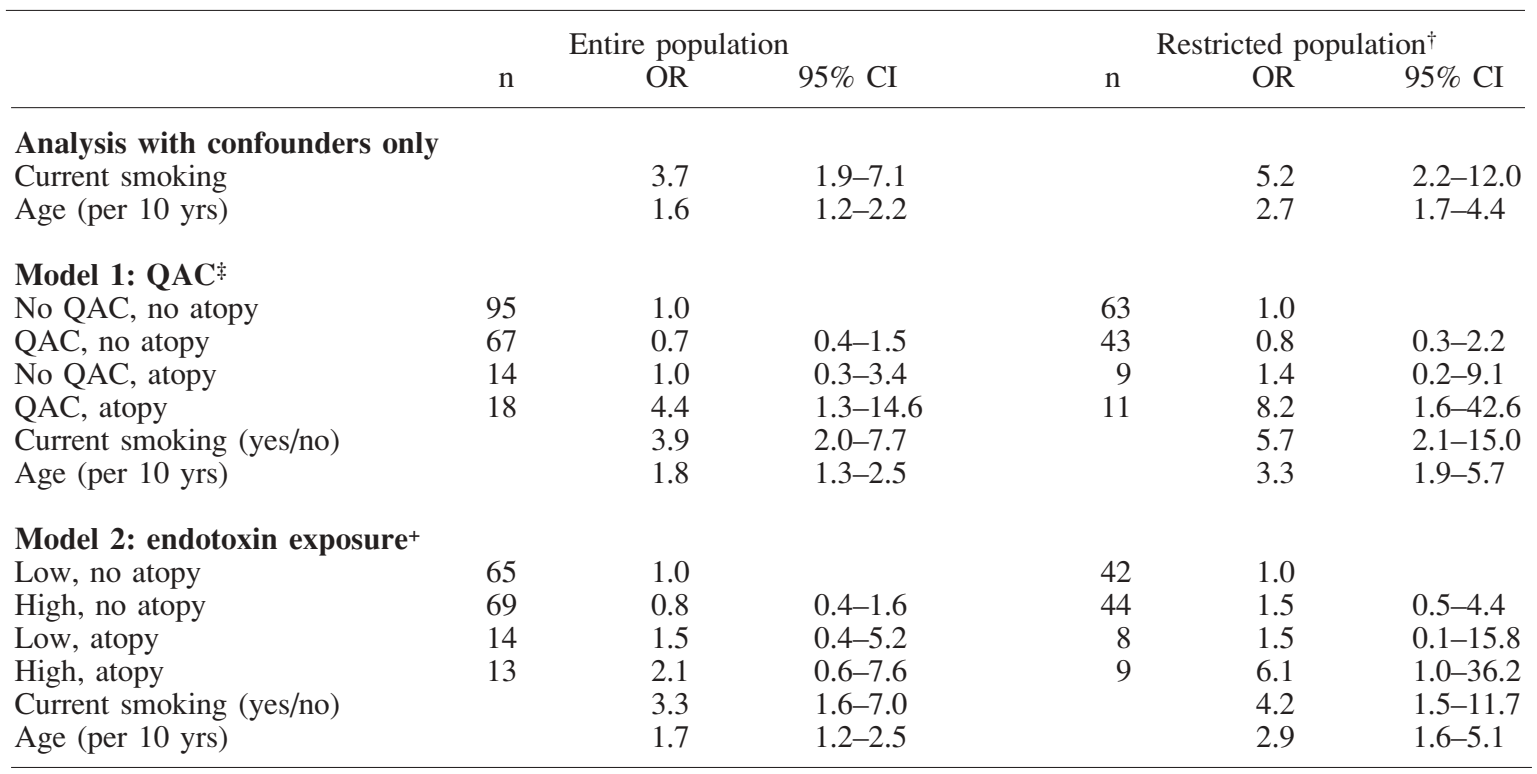

$\S$ : immunoglobulin $\mathrm{E}$ (IgE) to $\geq 1$ common allergen; ${ }^{\dagger}$ : chronic respiratory symptoms and PC10 histamine $\leq 16 \mathrm{mg} \cdot \mathrm{ml}^{-1} \mathrm{vs}$ no chronic respiratory symptoms and $\mathrm{PC} 10>16 \mathrm{mg} \cdot \mathrm{ml}^{-1}$; $\sharp$ QAC alone and QAC in combination with aldehydes or chloramine-T; ${ }^{+}$: low $\leq 101 \mathrm{ng}$ endotoxin $\cdot \mathrm{m}^{-3}$, high $>101 \mathrm{ng} \cdot \mathrm{m}^{-3}$. For abbreviations see legend to table 1 .

Similar analyses with dichotomized total IgE level and both types of exposure showed comparable but weaker trends than those presented in table 4.

\section{Discussion}

In this study, we found that IgE sensitization to common allergens occurred more frequently in farmers who used disinfectants containing only QACs, and moderately more frequently in farmers using QACs mixed with aldehydes. This suggests that atopic sensitization to common allergens might be caused by the use of disinfectants and is indicative of an adjuvant effect of the QAC-containing disinfectants. It was also shown that farmers with atopic sensitization to common allergens who also used disinfectants containing QACs had respiratory symptoms significantly more often than the other groups of pig farmers.

Associations between respiratory symptoms and risk factors were strongest within the population restricted according to bronchial hyperresponsiveness. Restriction was applied to realize a maximum contrast between those with and those without symptoms consistent with asthma. Since bronchial hyperresponsiveness is regarded as a hallmark of asthma, but is not in itself a specific method of defining asthma, we used the outcome of the histamine threshold test in addition to reported chronic respiratory symptoms. ToELle et al. [23] proposed a similar procedure to define asthma in epidemiology, although their criteria differed from ours. The criterion of bronchial hyperresponsiveness of $\mathrm{PC} 10 \leq 16$ $\mathrm{mg} \cdot \mathrm{mL}^{-1}$ used in our study could be the subject of discussion, but a more severe criterion would have limited the possibility of performing epidemiological analyses. The ORs for the association between respiratory symptoms and the use of QACs or atopic sensitization to common allergens (as independent variables) did not significantly differ from 1 , unlike the association between respiratory systems and both risk factors combined. This indicates that both risk factors need to be present in order to develop symptoms consistent with asthma.

The specific IgE antibodies studied were directed against allergens of house dust mite, grass and birch pollen and cat allergens, although no farmer showed positive titres against the latter. This panel of four allergens was expected to identify the majority of individuals with atopic sensitization to common allergens [24]. The observed associations with the use of QACs suggest that occupational exposure may induce sensitization to non-work-related allergens. In our population, 20 farmers had positive $\operatorname{IgE}$ against storage mites, which might be work-related. However, this did not explain the associations with common allergens, since excluding both those with IgE against storage mite and house dust mite yielded similar associations between specific sensitization and use of disinfectants.

The level of endotoxin exposure is high among pig farmers, and is thought to be an important aetiological factor in the development of respiratory effects [10]. In the present study, there was no indication that endotoxin leads to specific sensitization to common allergens. In the population restricted according to bronchial hyperresponsiveness, a strong association was observed between respiratory symptoms and the combination of specific IgE sensitization to common allergens and high endotoxin exposure $\left(>101 \mathrm{ng} \cdot \mathrm{m}^{-3}\right)$, but not with these factors independently.

The large confidence intervals both for the interaction between atopy and use of QACs, and atopy and endotoxin exposure separately, restricts conclusions regarding the strength of the interaction effects. The interactions observed could not be attributed to stronger atopic sensitization of 
the sensitized group with exposure to QACs or high endotoxin levels, compared to the sensitized group without exposure to QACs or with low endotoxin levels. Increased bronchial responsiveness to histamine in asthmatics after exposure to endotoxins [25] or QACs [26] may, in part, explain these interactions. It is also possible that atopics develop respiratory symptoms at lower exposure intensities of several nonallergenic agents than nonatopics. A larger airway sensitivity to endotoxins in atopics has recently been suggested by JACOBS et al. [27].

Selection bias seems unlikely to explain the results which suggest an adjuvant effect of QACs. Known potential predictors of positive IgE titres, such as childhood or familial history of allergic diseases, did not differ between farmers with and without QAC exposure. In our study, farmers were not selected because of exposure to disinfectants. Selection of the population of 194 farmers was based on respiratory symptoms. If the association presented in table 4 existed in the base population of 1,133 farmers, this potentially oversampled farmers with the combination of atopic sensitization and use of QACs. However, this did not influence our results, since associations between atopic sensitization and use of QAC were similar in symptomatic and asymptomatic farmers.

Misclassification of disinfectants is unlikely to have introduced a major bias, despite the cross-sectional study design in which type of disinfectants was not assessed prior to collection of serum for determination of IgE levels. All information on disinfectants was obtained by the same trained interviewer, who visited all farms and personally checked disinfectants present at that time. He was unaware of the respiratory symptoms of the farmers. Information on disinfection use among a subgroup of 86 pig farmers, acquired by means of an interview by phone $1.5 \mathrm{yrs}$ after initial data collection, showed that change of type of disinfectant was rare and independent of atopy, type of disinfectant and respiratory symptoms.

After evaluation of these forms of bias, an adjuvant effect of QAC remains the most plausible explanation for its observed association with specific IgE sensitization to common allergens. It should be realized that the sequence of events: disinfectant exposure, followed by atopic sensitization to common allergens and subsequent development of symptoms, cannot be studied in a crosssectional study. Other explanations of our findings seem unlikely, although a confirmatory longitudinal study seems warranted.

In our population of pig farmers, we observed strong associations between characteristics of the disinfection procedure, such as duration and spray pressure used during disinfection, and baseline lung function and chronic respiratory symptoms [28]. These associations were independent of the type of disinfectant. In other studies, respiratory health effects have been reported for disinfectants containing QACs, chloramine-T, glutaraldehyde and formaldehyde [18, 29-31]. QAC specific antibodies could not be demonstrated in an individual with occupational asthma following exposure to QACs [29], but have been found in individuals with muscle relaxant allergy [32]. Chloramine-T specific IgE antibodies have been demonstrated in individuals with chloramine-T induced asthma [18]. It is unclear whether aldehydes cause IgE-mediated asthmatic symptoms, although formaldehyde specific IgE antibodies have been demonstrated to be associated with skin problems, and discomfort in the upper airways [33, 34]. No farmers in our study had specific IgE to chloramine-T, and only two out of 40 using QACs had specific IgE to QAC. This finding does not support a role of disinfectant specific IgE mediated mechanisms in the associations observed.

Several authors have suggested that increased atopic sensitization due to exposure to nonallergenic air pollutants may be one of the mechanisms underlying the observed increase in prevalence of IgE mediated asthma $[35,36]$. This suggestion is based mainly on experimental animal studies, in which exposure to air pollutants preceding or concurrent with allergen exposure resulted in an increase in atopic sensitization [7-9]. So far, only active smoking has been found to enhance atopic sensitization in humans [37]. Exposure to disinfectants takes place about once a week, when disinfectants are dispersed with a high pressure spraying pistol. This activity generally takes less then $15 \mathrm{~min}$. This implies that even occasional short-term exposure may affect IgE sensitization to common allergens.

Several mechanisms have been suggested for the adjuvant effect of nonallergenic air pollutants. Adsorption of allergens to the adjuvant particles [8] is unlikely because of the nonconcurrent exposure to disinfectants and the allergens against which specific $\operatorname{IgE}$ antibodies were tested. Increased permeability of the bronchial epithelium, as suggested by HulBerT et al. [38], cannot be ruled out. Holt [39] mentioned interactive and toxic effects on pulmonary alveolar macrophages, which would disturb the immunoregulatory role of these cells in the $\operatorname{IgE}$ response, as a potential mechanism. In our study, the use of disinfectants containing only QACs was most strongly associated with specific IgE sensitization to common allergens. The QAC dimethyl dioctadecyl ammonium bromide has been shown to affect the humoral response and the activity of macrophages in mice and in vitro [11]. This favours some role for the latter mechanism.

In conclusion, the results of this study clearly suggest an increased risk of IgE sensitization to common aeroallergens among farmers using disinfectants containing quaternary ammonium compounds, which is potentially the result of an adjuvant effect. In addition, atopic sensitization in combination with use of quatenary ammonium compounds or with exposure to high endotoxin levels, seems to increase the risk of developing symptoms consistent with asthma. We have, thus, probably identified a co-factor for the risk of atopic sensitization and for the development of symptoms consistent with asthma. It is possible that similar effects exist for exposure to other nonallergenic agents in the occupational or general indoor or outdoor environment. To our knowledge, no studies have been reported that were designed to test this hypothesis. The role of exposure to nonallergenic compounds in asthma may, therefore, be largely underestimated.

Acknowledgements: The authors would like to thank D.S. Postma (Dept of Pulmonology, University of Groningen) and G. de Meer (Dept. of Epidemiology and Public Health, Wageningen Agricultural University) for critically reading the manuscript; M.M.J. Tielen (Animal Health Service in The Southern Netherlands) for his contributions to this study, and H. van Gisteren and employees of the Animal Health Service for their participation in data collection. 


\section{References}

1. O'Connor GT, Sparrow D, Weiss ST. The role of allergy and nonspecific airway hyperresponsiveness in the pathogenesis of chronic obstructive pulmonary disease. Am Rev Respir Dis 1989; 140: 225-252.

2. Björkstén B. Risk factors in early childhood for the development of atopic diseases. Allergy 1994; 49: 400-407.

3. Cullinan P, Newman Taylor AJ. Asthma in children: environmental factors. Br Med J 1994; 308: 1585-1586.

4. Ishizaki T, Koizumi K, Ikemori R, Ishiyama Y, Kushibiki E. Studies of prevalence of Japanese cedar pollinosis among the residents in a densely cultivated area. Ann Allergy 1987; 58: 265-270.

5. Molfino NA, Wright SC, Katz I, et al. Effect of low concentrations of ozone on inhaled allergen responses in asthmatic subjects. Lancet 1991; 338: 199-203.

6. Wjst M, Reitmeir P, Dold S, et al. Road traffic and adverse effects on respiratory health in children. $\mathrm{Br} \mathrm{Med}$ J 1993; 307: 596-600.

7. Biagini RE, Moorman WJ, Lewis TR, Bernstein IL. Ozone enhancement of platinum asthma in a primate model. Am Rev Respir Dis 1986; 134: 719-725.

8. Muranaka M, Suzuki S, Koizumi K, et al. Adjuvant activity of diesel exhaust particulates for the production of IgE antibody in mice. J Allergy Clin Immunol 1986; 77: 616-623.

9. Riedel F, Krämer M, Scheibenbogen C, Rieger CHL. Effects of $\mathrm{SO}_{2}$ exposure on allergic sensitization in the guinea-pig. J Allergy Clin Immunol 1988; 82: 527-534.

10. Rylander R, Donham KJ, Hjort C, Brouwer R, Heederik D. Effects of exposure to dust in swine confinement buildings: a working group report. Scand J Work Environ Health 1989; 15: 309-312.

11. Bloksma N, Reuver MJ de, Willers JM. Impaired macrophage functions as a possible basis of immunomodification by microbial agents, tilorone and dimethyldioctadecylammonium bromide. Antonie Van Leeuwenhoek 1983; 49: 13-22.

12. Coffman RI, Ohara J, Bond MW, Carty J, Zlotnik A Paul WE. B-cell stimulatory factor-1 enhances the IgE response of lipopolysaccharide-activated B-cells. J Immunol 1986; 136: $4538-4541$.

13. Biersteker K, Dijk WH van, Eissens JBMF, Geuns HA van. Ervaringen met geneeskundig onderzoek op CARA bij gemeentepersoneel te Rotterdam, 1970-1971. Tijdschr Soc Geneeskd 1974; 52: 158-162.

14. Cockcroft D, Killian D, Mellon J, Hargreave F. Bronchial reactivity to inhaled histamine; a method and clinical survey. Clin Allergy 1977; 7: 235-243.

15. Quanjer PhH, Tammelin GJ, Cotes JE, Pedersen OF, Peslin R, Yernault J-C. Lung volumes and forced ventilatory flaws. Report Working Party "Standardization of Lung Function Tests". European Coal and Steel Community. Eur Respir J 1993; 6 (Suppl. 16): 5-40.

16. Doekes G, Douwes J, Wouters I, de Wind S, Houba R, Hollander A. Enzyme immunoassays for total and allergen-specific IgE in population studies. Occup Environ Med 1996; 53: 63-70.

17. Wessels MW, Doekes G, Van Ieperen-Van Dijk AG, Koers WJ, Young E. IgE antibodies to Pityrosporum ovale in atopic dermatitis. Br J Dermatol 1991; 125: 227-232.

18. Kramps JA, Toorenenbergen AW van, Vooren PH van, Dijkman JH. Occupational asthma due to inhalation of chloramine-T. Int Arch Allergy Appl Immunol 1981; 64: $428-438$.

19. Hollander A, Heederik D, Versloot P, Douwes J. Inhibition and enhancement in the analysis of airborne endotoxin levels in various occupational environments. Am Ind Hyg Assoc J 1993; 54: 647-653.

20. Preller L, Kromhout H, Heederik H. Modelling longterm dust and endotoxin exposures in pig farmers. Scand J Work Environ Health 1995; 21: 504-512.

21. SAS/STAT guide for personal computers. Version 6 Edition. SAS Institute Inc., Cary, NC, 1985.

22. Rijcken B, Schouten JP, Weiss ST, Speizer FE, Lende $\mathrm{R}$ van der. The relationship of nonspecific bronchial responsiveness to respiratory symptoms in a random population sample. Am Rev Respir Dis 1987; 136: 62-68.

23. Toelle BG, Peat JK, Salome CM, Mellis CM, Woolcock AJ. Toward a definition of asthma for epidemiology. Am Rev Respir Dis 1992; 146: 633-637.

24. Kuehr J, Karmaus W, Forster J, et al. Sensitization to four common inhalant allergens within 302 nuclear families. Clin Exp Allergy 1993; 23: 600-605.

25. Michel O, Duchateau J, Sergysels R. Effects of inhaled endotoxin on bronchial reactivity in asthmatic and normal subjects. J Appl Physiol 1989; 66: 1059-1064.

26. Zhang YG, Wright WJ, Tam WK, Nguyen-Dang TH, Salome CM, Woolcock AJ. Effect of inhaled preservatives on asthmatic subjects. II. Benzalkonium chloride. Am Rev Respir Dis 1990; 141: 1405-1408.

27. Jacobs RR, Boehlecke B, Hage-Hamsten M van, Rylander R. Bronchial reactivity, atopy, and airway response to cotton dust. Am Rev Respir Dis 1993; 148: 19-24.

28. Preller L, Heederik D, Boleij JSM, Vogelzang PFJ, Tielen MJM. Lung function and chronic respiratory symptoms of pig farmers: focus on exposure to endotoxins and ammonia and use of disinfectants. Occup Environ Med 1995; 52: 654-660.

29. Bernstein JA, Stauder T, Bernstein DI, Bernstein IL. A combined respiratory and cutaneous hypersensitivity syndrome induced by work exposure to quaternary amines. J Allergy Clin Immunol 1994; 94: 257-259.

30. Chan-Yeung M, McMurren T, Catonio-Begley C, Lam S. Occupational asthma in a technologist exposed to glutaraldehyde. J Allergy Clin Immunol 1993; 91: 974-978.

31. Bardana EJ, Montanaro A. Formaldehyde: an analysis of its respiratory, cutaneous, and immunologic effects. Ann Allergy 1991; 66: 441-452.

32. Didier A, Cador D, Bongrand $\mathrm{P}$, et al. Role of the quaternary ammonium ion determinants in allergy to muscle relaxants. J Allergy Clin Immunol 1987; 79: 578-584.

33. Bernstein RS, Stayner LT, Elliott LJ, Kimbrough R, Falk $\mathrm{H}$, Blade L. Inhalation exposure to formaldehyde: an overview of its toxicology, epidemiology, monitoring and control. Am Ind Hyg Assoc J 1984; 45: 778-785.

34. Wilhelmsson B, Holmstrom M. Possible mechanisms of formaldehyde-induced discomfort in the upper airways. Scand J Work Environ Health 1992; 18: 403-407.

35. Holt PG. Environmental pollutants as co-factors in IgE production. Current Opinion Immunol 1989; 1: 643-646.

36. Molfino NA, Slutsky AS, Zamel N. The effects of air pollution on allergic bronchial responsiveness. Clin Exp Allergy 1992; 22: 667-672.

37. Venables KM, Dally MB, Nunn AJ, Stevens JF, et al. Smoking and occupational allergy in workers in a platinum refinery. $\mathrm{Br}$ Med $J$ 299; 1989: 939-942.

38. Hulbert WC, Walker DC, Jackson A, Hogg JC. Airway permeability to horseradish peroxidase in guinea-pigs: the repair phase after injury by cigarette smoke. Am Rev Respir Dis 1981; 123: 320-326.

39. Holt PG. Inflammation in organic dust-induced lung disease: mew approaches for research into underlying mechanisms. Am J Ind Med 1990; 17: 47-54. 